\title{
Association Between Interlukin 10 Gene Polymorphism And Susceptibility To Diabetic Kidney Disease
}

\begin{abstract}
Amany S Elshamy ${ }^{\mathrm{a}}$, Mohamed M. Elshafae ${ }^{\mathrm{b}}$, Hesham A. Eissa ${ }^{\mathrm{b}}$, Asmaa A. Elfallah ${ }^{\mathrm{b}}$, Saddam H. Abdelaziz $^{\mathrm{c}}$

${ }^{a}$ Department of clinical pathology, damanhour national medical institute, ${ }^{\mathrm{b}}$ deparmtnet of Clinical and Chemical Pathology, ${ }^{\mathrm{C}}$ department of Internal Medicine, Faculty of Medicine,

Background and rational: Interleukin-10 (IL-10) is a major anti-inflammatory and immunosuppressive cytokine that plays an important role in regulation of immune system. Its activity may be important for clinical outcome of diabetic kidney disease (DKD). This study aimed to evaluate the association between the genotypic and allelic frequencies of the IL-10 (-1082G/A) polymorphism and the risk of developing DKD in a group of Egyptian patients.
\end{abstract} Benha University, Egypt

Correspondence to: Amany

S Elshamy MSC, department of clinical pathology, damanhour national medical institute, Egypt, email: monadr44@gmail.com

Received:9 October 2019

Accepted:29 October 2019

BMJ 2019, vol 36, issue 2
Patients and Methods: The IL-10 (1082) G/A gene polymorphism was detected using PCR-RFLP in 50 subjects, 40 type 2 diabetic patients with diabetic kidney disease (DKD) and 10 diabetics without DKD as a control subjects. The subjects were divided in to 3 groups; (Group I), included 20 albuminuric patients, with A/C ratio > $30 \mathrm{mg} / \mathrm{g}$, (Group II), included 20 non albuminuric patients, with $\mathrm{A} / \mathrm{C}$ ratio < $30 \mathrm{mg} / \mathrm{g}$, and (Group III), 10 type 2 diabetic patients as controls without DKD.

Results: IL-10 gene variants showed statisticaly significant association in the different studied groups and the most frequent genotype in patients with DKD was GG genotype. Logistic regression analysis revealed that both urine albumin creatinine ratio (UACR) and e GFR were significant predictors of GG genotype, but UACR was much stronger predictor. ( $\mathrm{p}=0.005$ and 0.019 ) respectively.

Conclusion: The IL-10 (1082) G/A gene polymorphism might be associated with the risk of development of DKD in the studied patients. Moreover, the mutant $G$ allele of the polymorphism was associated with an increased risk of DKD compared to the wild A allele.

\section{Key Words:}

Diabetic kidney disease; interleukin 10 gene polymorphism; urine albumin creatinine ratio. 


\section{Introduction}

Chronic kidney disease (CKD) is one of the long term complications of diabetes mellitus (DM). After 10 to 20 years, approximately half of patients with type $2 \mathrm{DM}$ and one third with type $1 \mathrm{DM}$, will develop DKD. This renders $\mathrm{DM}$ as the leading cause of end stage renal disease (ESRD) (1). CKD is clinically defined by the presence of impaired renal function or elevated urinary albumin excretion, or both. Causes that may lead to renal dysfunction include hypertension, dyslipidemia, obesity, intrarenal vascular disease, acute kidney injury, renal ischemia, glomerular atherosclerosis and ageing-related nephron loss (2). DKD was originally described by Mogensen in the 1980s as a progressive disease that begins with the loss of small amounts of albumin into the urine $(30-300 \mathrm{mg} /$ day) that is known as microalbuminuria or occult or incipient nephropathy. When larger amounts of albumin are lost in the urine, and albuminuria becomes detectable by the dipstick urinalysis $(>300$ $\mathrm{mg}$ /day), the terms macroalbuminuria or overt nephropathy are used. This presentation was classically followed by a decline in the kidney function, renal impairment and finally ESRD (3). Some patients with type $1 \mathrm{DM}$ and most with type $2 \mathrm{DM}$, do not follow this classical course in modern clinical practice. For example, it was found that many patients with DM and renal impairment do not show increased urinary albumin loss (4). Indeed, half of the $28 \%$ of the United Kingdom Prospective Diabetes Study (UKPDS) cohort who had an estimated glomerular filtration rate (eGFR) $<60$ $\mathrm{ml} / \mathrm{min} / 1.73 \mathrm{~m}^{2}$, did not have preceding albuminuria (5). Even in the Diabetes Control and Complications Trial (DCCT), 40\% had never progressed to overt nephropathy of the $11 \%$ of patients with type 1 diabetes who developed an eGFR of $<60 \mathrm{ml} / \mathrm{min} / 1.73 \mathrm{~m}^{2}$ (6).
Although DKD is traditionally considered as nonimmune disease, inflammation has been recognized to have a central role in the onset and progression of DKD. Circulating levels of proinflammatory cytokines are increased in diabetic patients and correlate with increased albuminuria (7). Interleukin-10 (IL-10) is a multifunctional cytokine which has predominantly anti-inflammatory and immunosuppressive effects by inhibiting the production of proinflammatory cytokines, antigen presentation, and proliferation of $\mathrm{T}$ cells. The gene encoding human IL-10 is located on chromosome 1q21-32 (8). Polymorphism of the gene coding for IL-10 is suggested to cause loss of its anti-inflammatory effect on kidney and subsequent development of DKD (9).

\section{Subjects and methods}

\section{SUBJECTS:}

This case control study was performed in the Central Laboratory of Benha Faculty of Medicine, on a total number of 50 subjects, recruited from internal medicine department of Benha University Hospitals during the period from May 2017 to May 2018. The study was approved by ethical committee of Benha faculty of medicine and an informed written consent was obtained from all the participants.Subjects enrolled in this study were classified into three groups:

Group 1 included 20 type 2 diabetic patients complicated with diabetic kidney disease (DKD) with albuminuria $\left(\mathrm{eGFR}<60 \mathrm{ml} / \mathrm{min} / 1.73 \mathrm{~m}^{2}\right.$ and $\left.\mathrm{ACR}>30 \mathrm{mg} / \mathrm{g}\right)$.

Group 2 included 20 type 2 diabetic patients complicated with DKD without albuminuria (eGFR $<60 \mathrm{ml} / \mathrm{min} / 1.73 \mathrm{~m}^{2}$ and $\mathrm{ACR}<30 \mathrm{mg} / \mathrm{g}$ ). 
Group 3 included 10 type 2 diabetic patients without DKD (eGFR $>60 \mathrm{ml} / \mathrm{min} / 1.73 \mathrm{~m}^{2}$ and $\mathrm{ACR}<30 \mathrm{mg} / \mathrm{g}$ ) serving as a control group according to ethical consideration.

All participants were subjected to: full history taking, clinical examination and laboratory investigations

\section{Sample Collection:}

Five mLs of venous blood were withdrawn from each subject after an overnight fasting, then divided into two parts:

1- The first part $2 \mathrm{mLs}$ was collected in sterile ethylene diamine tetra acetate "EDTA" tubes then divided into two aliquots, one was used for the glycosylated hemoglobin assay and the other was stored at $-80{ }^{\circ} \mathrm{C}$ till time of assay for subsequent DNA extraction.

2- The second part $3 \mathrm{mLs}$ was collected in serum separating tubes. Clotted samples were centrifuged within one hour of sampling, at $3000 \mathrm{rpm}$ for 15 minutes. The resultant serum was used for the clinical chemistry tests.

\section{Methods}

\section{A. Routine Tests:}

\section{Fasting Blood Glucose and kidney function tests:}

Fasting blood glucose, total cholesterol, triglycerides, HDL-c, LDL-c and serum creatinine were done using Biosystems A15 auto-analyzer, Barcelona, Spain.

\section{Glycated Haemoglobin (HbA1c):}

HbA1c measurement is based on a turbidimetric inhibition immunoassay (TINIA) principle on Dimension clinical chemistry system using kits supplied by Siemens.

\section{Estimated GFR (eGFR):}

Using the Chronic Kidney Disease Epidemiology Collaboration (CKD-EPI), eGFR was calculated. Calculators are available from http://www .nkdep.nih.gov. An eGFR $<60 \mathrm{ml} / \mathrm{min} / 1.73 \mathrm{~m}^{2}$ is generally considered abnormal (10).

\section{B. Special Investigations:}

1- Albumin creatinine ratio (A/C ratio) was measured using Biosystems reagent kits provided by Biosystems, SA. Costa Brava 30, 08030, Barcelona, Spain. A convenient quantitative method for measuring low concentration of albumin, creatinine ratio in urine was used.

2- Genomic DNA extraction and analysis: Extraction of genomic DNA was done by whole blood genomic DNA purification mini kit (ZYMO SEARCH) (Catalog Nos. \# D3024- D3025) USA, according to the manufacturer instructions. IL-10 gene polymorphism at position -1082 results from the substitution of guanine with adenine. The region containing the polymorphism was amplified by PCR-RFLP using IL-10 forward and reverse primers, (5'- CTC GTC GCA ACC CAA CTG - $3^{\prime}$ ) and (5'- ACT TTC ATC TTA CCT ATC CCT ACT TCC -3') respectively. A $50 \mu 1$ reaction mix contained $1 \mu \mathrm{l}$ forward primer, $1 \mu 1$ reverse primer, $5 \mu 1$ template DNA, $18 \mu 1$ nuclease-free water and $25 \mu 1$ dream Taq green PCR master mix (2X), then the experiment was created using thermal cycler program described in (table 1). The amplified products were digested with MnLI restriction enzyme, specific for the target polymorphism. The post digested products were analyzed by gel electrophoresis on 1-2\% agarose gel containing ethidium bromide and visualized by UV trans-illumination for genotype calling The PCR product was analyzed by using gel electrophoresis and visualized by ethidium bromide staining. The homozygous AA had a single undigested band at $139 \mathrm{bp}$, while homozygous GG had two bands at 101 and $38 \mathrm{bp}$ and heterozygous GA had three bands at 139, 101 and 38bp at the -1082 locus (fig. 1). 
Table (1): Thermal cycler program (BIO-RAD, Singapore):

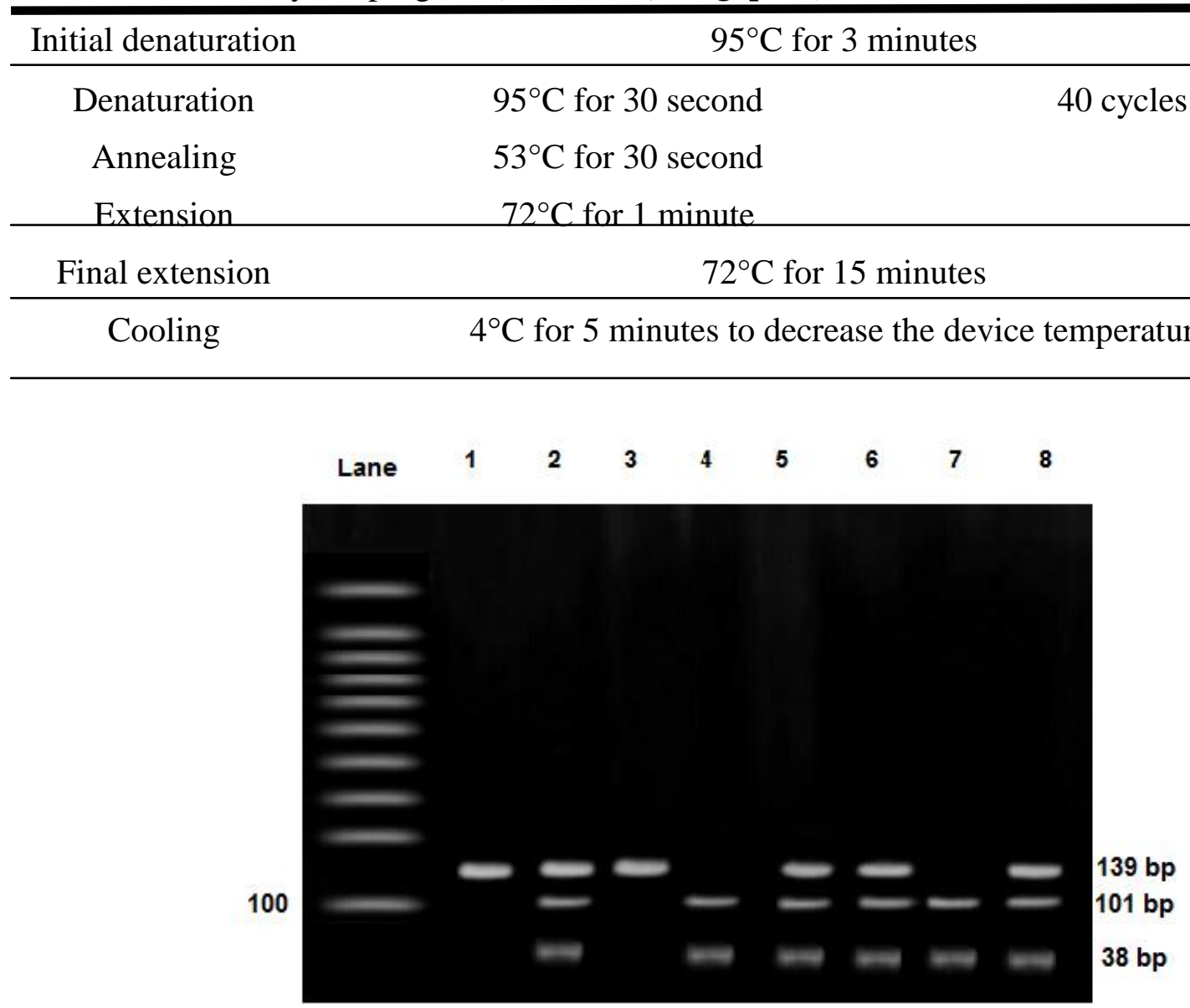

Figure (1): Representative agarose gel electrophoresis for detection of IL-10 (1082 G/A) gene polymorphism. Lane: 100 bp molecular weight marker, lanes 1 and 3: homozygous AA genotype; lanes 4 and 7: homozygous GG genotype and lanes 2, 5, 6 and 8 heterozygous GA genotype.

\section{Statistical methods:}

Data management and statistical analysis were performed using Statistical Package for Social Sciences (SPSS) vs. 16 software (SPSS, Inc, Chicago, IL, USA). Numerical data were presented as mean \pm standard deviation while categorical data were presented as numbers and percentages. Comparisons between groups for numerical data were done using Kruskal Wallis test. Categorical data were analyzed with $\chi^{2}$ (chi square) test or Fisher's exact test when appropriate. Odds ratio with $95 \%$ Confidence interval was calculated for genotypes. Pvalues $<0.05$ were considered significant.

\section{Results:}

\section{Patient characteristics and clinical investigations:}

Age, sex, CVS complications and waist hip ratio, there were no significant difference between the three studied groups, while retinopathy, hypertension, triglycerides, total cholesterol and LDL-c, there were significant differences between the three studied groups. Comparing group I to the other two groups, 
there was significant difference in duration of DM, HbA1c, serum creatinine, UACR and eGFR. (table 2).

\section{Frequency of IL-10 (1082) G/A gene polymorphism:}

The genotype distribution of IL-10 (1082) G/A gene polymorphism, was different between the control group (AA 60.0\%, GA $20.0 \%$, GG $20.0 \%$ ) and the DKD patients (AA $17.5 \%$, GA $37.5 \%$, GG $45.0 \%$ ). The frequency of the mutant $\mathrm{G}$ allele in control group was $30.0 \%$, while it was $63.8 \%$ in DKD group (table 3).

There was a statisticaly significant difference between type 2 diabetic patients with DKD and type 2 diabetic patients without DKD regarding GG and GA genotype distribution. $P$ values were 0.028 and 0.046 respectively, OR (95\% C.I) were $7.7(1.2-47.7)$ and 6.4 (1.0340.2) respectively. Moreover, there was statisticaly significant difference between patients with albuminuria and without albuminuria as regard $\mathrm{G}$ allele ( $\mathrm{P}$ value $=0.009)$, OR $(95 \%$ C.I $)=4.1(1.4-11.8)$ (table 3).

The genotype distribution of IL-10 (-1082) G/A gene polymorphism in DKD patients with albuminuria (group I), was AA $10.0 \%$, GA $25.0 \%$, GG $65.0 \%$ versus AA $25.0 \%$, GA $50.0 \%$, GG $25.0 \%$ in those without albuminuria (group II). The frequency of the mutant $\mathrm{G}$ allele in group I was $77.5 \%$, while it was $50.0 \%$ in group II (table 4).

There was no statisticaly significant difference between patients with albuminuria and without albuminuria as regard GG and GA genotype distribution. $\mathrm{P}$ values were 0.058 and 0.82 respectively, OR (95\% C.I) were 6.5 (0.93 $-45.1)$ and $1.3(0.17-8.8)$ respectively. There was a statisticaly significant difference between patients with albuminuria and without albuminuria as regard $\mathrm{G}$ allele $(\mathrm{P}$ value
$=0.012)$, OR $(95 \%$ C.I $)=3.4(1.3-9.05)($ table 4).

\section{Association between IL-10 (1082) G/A gene polymorphism and eGFR categories:}

In the present study, genotypes and alleles of IL-10 (1082) G/A polymorphism have been distributed according to eGFR categories, using KIDGO 2012 eGFR classification but G1 and G2 categories couldnot be separated because Chronic Kidney Disease Epidemiology Collaboration (CKD-EPI) equation have been used for estimating GFR, which is available from http://www.nkdep.nih.gov. This equation is reporting eGFR values greater than or equal 60 simply as $\geq 60 \mathrm{ml} / \mathrm{min} / 1.73 \mathrm{~m}^{2}$, not an exact number(10).

Twenty percent of G1+G2 categories is GG, $20 \%$ is GA, and $60 \%$ is AA, while $20 \%$ of G3a category is $\mathrm{GG}, 60 \%$ is $\mathrm{GA}$, and $20 \%$ is AA, where $33.3 \%$ of G3b category is GG, $44.4 \%$ is GA, and $22.2 \%$ is AA. Moreover $50 \%$ of G4 category is GG, $12.5 \%$ is $\mathrm{GA}$, and $37.5 \%$ is AA, while $69.2 \%$ of G5 category is GG, $30.8 \%$ is GA, and none was AA genotype (table 5).

In albuminuric DKD group, $35 \%$ of patients are $\mathrm{G} 4$ and $65 \%$ are G5. In non albuminuric DKD group, $50 \%$ of patients are G3a, $45 \%$ are G3b, and $5 \%$ are G4, while $100 \%$ of diabetics without DKD are G1 and G2 (table 6)

\section{Characteristics of patients according to IL-10 (1082) G/A polymorphism:}

In group I there was significant difference between GG genotype and hypertension, UACR, eGFR and serum creatinine, while there was no significant difference regarding retinopathy and CVS complications. In (group II) there was no significant difference between GG genotype and hypertension, retinopathy, CVS complications, UACR, eGFR and serum creatinine, while there was 
significant difference between AA genotype and retinopathy.

\section{Roc curve and logistic regression} analysis for the prediction of IL-10 (1082)

\section{GG genotype:}

ROC curve and logistic analysis revealed that both UACR and e GFR are significant predictors of GG genotype. Patients with
$\mathrm{UACR} \geq 407.5 \mathrm{mg} / \mathrm{g}$ is 34.6 higher risk to have GG genotype than lower levels of UACR, while patient with eGFR $\leq 13.5$ $\mathrm{ml} / \mathrm{min} . / 1.73 \mathrm{~m}^{2}$ is 15.8 higher risk to have GG genotype than higher levels of eGFR. This suggests that UACR is much more associated with the presence of GG genotype than eGFR. ( $\mathrm{P}$ value $=0.005$ and 0.019 ) respectively (table 7 and table 8).

Table (2): The clinical data of the three studied groups.

\begin{tabular}{|c|c|c|c|c|}
\hline Variable & $\begin{array}{l}\text { Group I }(\mathrm{n}=\mathbf{2 0}) \\
\text { (DKD with albuminuria) }\end{array}$ & $\begin{array}{l}\text { Group II }(\mathbf{n}=20) \\
\text { (DKD without } \\
\text { albuminuria) }\end{array}$ & $\begin{array}{c}\text { Group III (n=10) } \\
\text { (DM without DKD) } \\
\text { Control group }\end{array}$ & $\begin{array}{c}\text { P } \\
\text { value }\end{array}$ \\
\hline & $\pm \mathrm{SD}$ & $\pm \mathrm{SD}$ & $\pm \mathrm{SD}$ & \\
\hline ge (years) & $56.5 \pm 5.5$ & $52.8 \pm 8.1$ & $53.6 \pm 5.08$ & 0.19 \\
\hline Vaist hip ratio & $0.90 \pm 0.03$ & $0.89 \pm 0.05$ & $0.89 \pm 0.04$ & 0.69 \\
\hline uration of DM (years) & $18.7 \pm 5.48$ & $11.1 \pm 3.35$ & $9.5 \pm 3.17$ & $<0.001$ \\
\hline lbA1c (\%) & $8.94 \pm 0.77$ & $6.87 \pm 0.20$ & $6.63 \pm 0.13$ & 0.008 \\
\hline riglycerides (mg/dl) & $223.2 \pm 106.7$ & $262.6 \pm 109.9$ & $118.8 \pm 34.9$ & 0.011 \\
\hline otal cholesterol (mg/dl) & $197.3 \pm 42.5$ & $212.4 \pm 30.6$ & $115.7 \pm 17.6$ & $<0.001$ \\
\hline [DL-c (mg/dl) & $47 \pm 5.7$ & $49.7 \pm 7.3$ & $52 \pm 6.9$ & 0.170 \\
\hline DL-c (mg/dl) & $99.2 \pm 39.9$ & $102.3 \pm 36.7$ & $30.2 \pm 12.2$ & 0.03 \\
\hline erum creatinine (mg/dl) & $4.6 \pm 1.14$ & $2.2 \pm 0.54$ & $1.05 \pm 0.20$ & $<0.001$ \\
\hline $\operatorname{ACR}(\mathrm{mg} / \mathrm{g})$ & $467.9 \pm 159.8$ & $22.8 \pm 4.15$ & $11.1 \pm 8.2$ & $<0.001$ \\
\hline $\operatorname{GFR}\left(\mathrm{ml} / \mathrm{min} / \mathbf{1 . 7 3 m ^ { 2 } )}\right.$ & $14.3 \pm 5.5$ & $42.6 \pm 9.8$ & $>60$ & $<0.001$ \\
\hline
\end{tabular}


Table (3): Frequency distribution of (1082) G/A polymorphism of IL-10 gene in type 2 diabetic patients with and without DKD.

\begin{tabular}{|c|c|c|c|c|c|c|c|}
\hline \multirow[t]{2}{*}{ IL-10 } & & \multicolumn{2}{|c|}{$\begin{array}{l}\text { DKD patients } \\
\qquad(\mathrm{n}=40)\end{array}$} & \multicolumn{2}{|c|}{$\begin{array}{c}\text { DM without DKD } \\
(\mathbf{n}=\mathbf{1 0})\end{array}$} & \multirow[t]{2}{*}{$\begin{array}{c}\text { OR } \\
(95 \% \mathrm{CI})\end{array}$} & \multirow[t]{2}{*}{$\mathbf{P}$} \\
\hline & & No. & $\%$ & No. & $\%$ & & \\
\hline \multirow[t]{3}{*}{ Genotypes } & GG & 18 & 45.0 & 2 & 20.0 & $\begin{array}{l}7.7 \\
(1.2-47.7)\end{array}$ & $0.028(\mathrm{~S})$ \\
\hline & GA & 15 & 37.5 & 2 & 20.0 & $\begin{array}{l}6.4 \\
(1.03-40.2)\end{array}$ & $0.046(\mathrm{~S})$ \\
\hline & AA & 7 & 17.5 & 6 & 60.0 & & ---- \\
\hline \multirow[t]{2}{*}{ Allele } & G & 51 & 63.8 & 6 & 30.0 & \multirow{2}{*}{$\begin{array}{l}4.1 \\
(1.4-11.8)\end{array}$} & $0.009(\mathrm{~S})$ \\
\hline & A & 29 & 36.3 & 14 & 70.0 & & \\
\hline
\end{tabular}

Table (4): Frequency distribution of (1082) G/A polymorphism of IL-10 gene in DKD patients with and without albuminuria.

\begin{tabular}{|c|c|c|c|c|c|c|c|}
\hline \multirow[t]{2}{*}{ IL-10 } & & \multicolumn{2}{|c|}{$\begin{array}{c}\text { DKD with } \\
\text { albuminuria } \\
(\mathrm{n}=\mathbf{2 0})\end{array}$} & \multicolumn{2}{|c|}{$\begin{array}{c}\text { DKD without } \\
\text { albuminuria } \\
(\mathbf{n}=20)\end{array}$} & \multirow[t]{2}{*}{$\begin{array}{c}\text { OR } \\
(95 \% \mathrm{CI})\end{array}$} & \multirow[t]{2}{*}{$\mathbf{P}$} \\
\hline & & No. & $\%$ & No. & $\%$ & & \\
\hline \multirow[t]{3}{*}{ Genotypes } & GG & 13 & 65.0 & 5 & 25.0 & $\begin{array}{c}6.5 \\
(0.93-45.1)\end{array}$ & $0.058(\mathrm{NS})$ \\
\hline & GA & 5 & 25.0 & 10 & 50.0 & $\begin{array}{c}1.3 \\
(0.17-8.8)\end{array}$ & $\begin{array}{l}0.82 \\
(\mathrm{NS})\end{array}$ \\
\hline & AA & 2 & 10.0 & 5 & 25.0 & & $\begin{array}{l}0.24 \\
\text { (NS) }\end{array}$ \\
\hline \multirow[t]{2}{*}{ Allele } & $\mathrm{G}$ & 31 & 77.5 & 20 & 50.0 & 3.4 & 0.012 \\
\hline & A & 9 & 22.5 & 20 & 50.0 & $(1.3-9.05)$ & (S) \\
\hline
\end{tabular}

Table (5): IL-10 (1082 G/A) genotype frequency as regard GFR classification in the studied groups.

\begin{tabular}{|c|c|c|c|c|c|c|c|c|}
\hline & & & \multicolumn{5}{|c|}{ GFR class } & \multirow[t]{2}{*}{ Total } \\
\hline & & & G1/ G2 & G3a & G3b & G4 & G5 & \\
\hline \multirow[t]{5}{*}{ Genotype } & GG & Count & 2 & 2 & 3 & 4 & 9 & 20 \\
\hline & & $\%$ within GFR class & $20.0 \%$ & $20.0 \%$ & $33.3 \%$ & $50.0 \%$ & $\begin{array}{l}69.2 \% \\
4\end{array}$ & $40.0 \%$ \\
\hline & GA & $\begin{array}{l}\text { Count } \\
\% \text { within GFR class }\end{array}$ & $\begin{array}{c}2 \\
20.0 \%\end{array}$ & $\begin{array}{c}6 \\
60.0 \%\end{array}$ & $\begin{array}{c}4 \\
44.4 \%\end{array}$ & $\begin{array}{c}1 \\
12.5 \%\end{array}$ & $\begin{array}{c}4 \\
30.8 \%\end{array}$ & $\begin{array}{c}17 \\
34.0 \%\end{array}$ \\
\hline & AA & Count & 6 & 2 & 2 & 3 & 0 & 13 \\
\hline & & $\%$ within GFR class & $60.0 \%$ & $20.0 \%$ & $22.2 \%$ & $37.5 \%$ & $.0 \%$ & $26.0 \%$ \\
\hline \multirow[t]{2}{*}{ Total } & & Count & 10 & 10 & 9 & 8 & 13 & 50 \\
\hline & & $\%$ within GFR class & $100.0 \%$ & $100.0 \%$ & $100.0 \%$ & $100.0 \%$ & $100.0 \%$ & $100.0 \%$ \\
\hline
\end{tabular}


Table (6): Comparison between the studied groups as regard GFR classification.

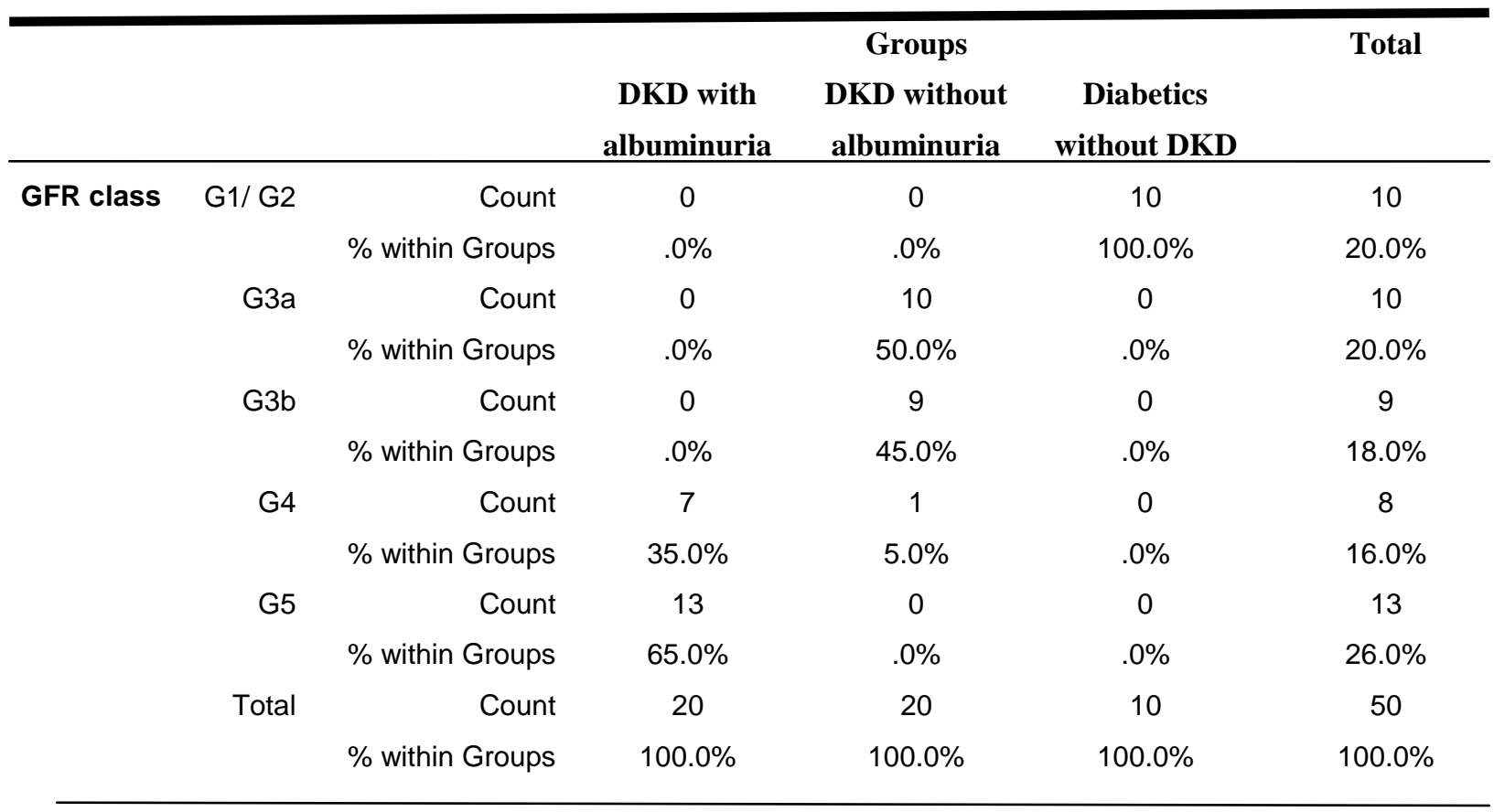

Table (7): Logistic regression analysis for the prediction of IL-10 (1082) GG genotype.

\begin{tabular}{rcccc}
\hline Variable & $\boldsymbol{\beta}$ & OR & $\mathbf{9 5 \%} \mathbf{C I}$ & $\mathbf{P}$ \\
\hline UACR $\geq \mathbf{4 0 7 . 5}$ & 21.7 & 34.6 & $5.9-305.1$ & $0.005(\mathrm{~S})$ \\
$\mathbf{\text { eGFR }} \leq \mathbf{1 3 . 5}$ & 19.4 & 15.8 & $3.6-137.9$ & $0.019(\mathrm{~S})$ \\
\hline
\end{tabular}

Table (8): Cut off value of both UACR and eGFR in albuminuric DKD..

\begin{tabular}{|c|c|c|c|c|c|c|c|c|c|}
\hline Variable & cutoff & Sens\% & Spec\% & PPV\% & NPV\% & Accuracy \% & AUC & $95 \% \mathrm{CI}$ & $\mathbf{P}$ \\
\hline UACR & $\geq 407.5$ & $92.3 \%$ & $85.7 \%$ & $92.3 \%$ & $85.7 \%$ & $90 \%$ & 0.879 & $0.69-1.0$ & $\begin{array}{l}0.006 \\
(\mathrm{~S})\end{array}$ \\
\hline eGFR & $\leq 13.5$ & $76.9 \%$ & $85.7 \%$ & $90.9 \%$ & $66.7 \%$ & $80 \%$ & 0.861 & $0.71-1.0$ & $\begin{array}{l}0.008 \\
(\mathrm{~S})\end{array}$ \\
\hline
\end{tabular}

\section{Discussion}

Chronic kidney diseases has affected millions of people all over the world, and has been known to be a worldwide public health problem. DKD is a common and serious complication of diabetes and have been identified as the leading cause of ESRD (11).

In the kidney, Interlukin -10 is locally expressed in the mesangial and endothelial cells, where it acts as an autocrine cell growth factor. IL-10also induces the proliferation of mesangial 
cells of the kidney through increasing production of growth factors, cytokines, and chemokines. This, in turn, leads to structural intraglomerular and tubulointerstitial changes, such as cell hypertrophy, thickening of the glomerular basement membrane, accumulation of mesangial matrix, and overt proteinuria. These pathological changes accelerate disease progression to renal failure and ESRD (12).

One of the main functions of IL- 10 is to control inflammation, thus, the low expression and/or gene polymorphism of IL-10 would be expected to cause renal damage due to the loss of anti-inflammatory protection (13).

This case control study was conducted on fifty subjects, 40 patients with type 2 DM complicated with DKD and 10 type 2 DM without DKD subjects seving as controls. Subjects were classified into 3 groups according to their albumin creatinine ratio (ACR).

In this study HbA1C showed statistically significant increase between group I and group III. This goes in line with a study by Erdogan et $\boldsymbol{a l}$ (14). This is due to irreversible binding of glucose to proteins in the kidneys and circulation which results into formation of advanced glycation end products (AGEs) that can form complex cross-links over years and contribute to renal damage (15).

In contrary, this study revealed nonsignificant difference in HbA1c levels between group II and group III. This result is consistent with another study made by Penno et al (16). They found that normal or mildly elevated $\mathrm{HbA} 1 \mathrm{c}$ levels is associated with non albuminuric DKD, this finding supports the hypothesis that diabetes leads to the development of non albuminuric DKD via pathways which are separate from hyperglycemia (17).

The present study showed a significant increase in lipid profile (total cholesterol, LDL-c, and triglycerides) in albuminuric group compared to non albuminuric group. This was agreed by Mottl et al. (18). They concluded that The concentration of total cholesterol, LDL-c, and triglycerides rises with increasing albumin excretion rate (AER). This is because of urinary protein loss that stimulates an increased LDL-c synthesis by the liver. It was reported that proteinuria with the resultant hypoalbuminemia leads to an upregulation of 3-hydroxy-3methylglutaryl CoA reductase with a consequent hypercholesterolemia. Impaired clearance of chylomicrons and VLDL has emerged as the main factor for the increased serum triglyceride concentration .

In the current study there was a significant increase in blood pressure between group $\mathbf{I}$ and group III. Bakris et al (19). documented that the significant difference, regarding HTN in albuminuric chronic kidney disease (ALB-CKD), is supported by the association between HTN and albuminuria. Multiple mechanisms can cause development of HTN in patients with DKD, including inappropriate activation of the renin angiotensin aldosterone system (RAAS), volume expansion due to increased sodium reabsorption, peripheral vasoconstriction, upregulation of endothelin 1, inflammation, and downregulation of nitric oxide. These factors contribute to the development of kidney disease and increase the risk for albuminuria

Non-significant difference was found between group II and group III as regard HTN this finding was opposed by another study (17). They found that the prevalence of normoalbuminuric chronic kidney disease (NA-CKD) is significantly lower in those with poorly controlled HTN.

The present study showed a significant difference in diabetic retinopathy (DR) between DKD patients (group I and II) and diabetic patients without DKD (group III). The association between albuminuria and DR which 
was observed in this study could be explained by the view that albuminuria might cause a state of generalized vascular dysfunction. Also, albuminuria and DR share common risk factors (duration of diabetes, high HbA1c levels and elevated blood pressure) (20).

This study showed a significant increase in UACR between group I and group II. This result goes in line with the United Kingdom Prospective Diabetes Study (UKPDS). They found that nearly $2 \%$ per year of DKD patients with T2DM progressed from normo- to microalbuminuria and from micro- to macroalbuminuria. After a median of 15 years of diagnosis, $40 \%$ of patients developed albuminuria, and 30\% developed eGFR $<60$ $\mathrm{ml} / \mathrm{min}$ per $1.73 \mathrm{~m}^{2}$. They also found that, $60 \%$ of those patients who developed kidney functional impairment did not have preceding albuminuria, and $40 \%$ never developed albuminuria during their study (21).

It is noteworthy that eGFR showed a significant decrease in group I compared to group II. This was consistent with another study (22), which revealed a correlation between reduction in functional nephron number (decreased eGFR) and progressive increase in AER. Hyperfiltration is hypothesized to be a precursor of intraglomerular hypertension which leads to albuminuria. Changes in systemic arterial pressure and changes in efferent and afferent arteriolar resistances are the causes of increased glomerular capillary hydraulic pressure. In the absence of treatment, GFR then falls progressively in parallel with a more rise in albuminuria which may lead to ESRD .

Also this study revealed that serum creatinine is significantly increased between group I and group II DKD. This was explained in another study (17), they calcified that the poor glycemic control (high HbA1c) in ALB-CKD leads to more renal damage and subsequent higher serum creatinine levels than in NA-CKD. These findings support the fact that albuminuria is considered to be a dynamic, fluctuating condition rather than being a linearly progressive process. Accelerated vascular disease, renal aging and masking of albuminuria by RAAS inhibitors are potential pathogenic alternatives to the underlying mechanisms of NA-CKD.

As regard the UKPDS by Retnakaran et al., (23), which supported the concept that an increase in AER and a decrease in GFR are complementary rather than obligatory manifestations of diabetic CKD, the presence or absence of albuminuria should therefore be interpreted as an important, but not the sole, risk marker that should be evaluated when stratifying the risk of progressive DKD in a patient.

IL-10 plays an important role in the regulation and maintenance of normal renal function, and abnormal IL-10 expression contributes to acute kidney injury and progressive chronic renal failure. Considering that the main function of IL10 is to control inflammation, this scenario seems to be a paradox, as the low expression of IL-10 would be expected to be detrimental to renal function due to the loss of antiinflammatory protection (13).

Polymorphisms which occur on the gene coding IL-10 leads to diabetic kidney disease by losing of its anti-inflammatory and immunosuppressive protection in the kidney. The best identified polymorphism is (1082) G/A which occurs by substitution of guanine on $1082^{\text {th }}$ position with adenine. This leads to amino acid change, deformity in the three-dimensional structure and reduction in its function (24).

In this study, considering GG genotype as the mutant gene and AA as the wild one, the GG genotype of IL-10 (1082 G/A) gene polymorphism is significantly associated with the occurrence of DKD. This result was agreed by $\boldsymbol{a}$ previous study (25), that reported an 
association between the GG genotype of the IL10 (1082G/A) polymorphism and an increased susceptibility to ESRD in German patients (table 3).

Conversely to another study (26) they concluded that the AA genotype of the IL-10 (1082 G/A) polymorphism was associated with the increased risk of ESRD in Chinese type 2 diabetic patients as compared with subjects without both diabetes and kidney disease.

On the other hand, Erdogan et al (14) revealed that IL-10 (1082 G/A) gene polymorphism was not associated with the risk of the development of nephropathy.

In the current study, frequent distribution of the different genotypes yielded non-significant association between group I and group II DKD, while there was a significant difference between both groups as regard alleles. The $\mathrm{G}$ allele was significantly higher in group I than group II (table 4).

In the present study there was no significant association between retinopathy and IL-10 (1082G/A) gene polymorphism in group $\mathbf{I}$, while there was a significant association between them in group II. This is consistent with a study made by Dace et al (27), they concluded the association between IL-10 gene polymorphism and retinopathy by demonstrating the effect of IL-10 in promoting retinal neovascularization in a mouse model. Intraocular neovascularization, which is characterized by abnormal retinal or choroidal angiogenesis, is well known to be a major cause of decreased vision in patients with proliferative diabetic retinopathy (PDR).

Furthermore, a statistically significant positive correlation between IL-10 (1082G/A) gene polymorphism, and hypertension in group I was found, in the current study while there was no significant correlation between them in group II.
As reviewed by Timasheva et al (28), association of IL-10 polymorphism with HTN, also explains the role of inflammation in the genesis of hypertension by inducing a pro-inflammatory response. In fact, IL-10 is an anti-inflammatory cytokine and downregulates proinflammatory production of TNF- $\alpha$ and IL- 6 . Angiotensin II stimulates interleukin-6 release which elicits a direct inflammatory response in smooth muscle cells; then IL-6 induces the synthesis of acute phase reactants, such as CRP and angiotensinogen. The hypothesis that CRP inhibits the production of nitric oxide by endothelial cells, which could lead to impaired vasomotor tone and vasoconstriction. CRP has been known to increase the expression of such endothelium-derived vasoconstrictors as endothelin-1.

The present study showed that there was a significant association between GG genotype of IL-10 (1082G/A) gene polymorphism and (UACR and eGFR) in group I DKD. Polina et al(29), results were in agreement with the current study, as they found that patients with GG genotype have lower eGFR compared to those with AG and AA genotypes, while this significant association was missed in group II DKD.

In this study, as regard eGFR categories, G allele was non significantly associated with severe decreased eGFR. GA genotype of IL-10 gene was found to be associated with increased risk of mildly to moderately decreased eGFR (G3a), whereas GG genotype is associated with increased risk of kidney failure (G5) as compared with AA genotype.

These findings are in accordance with a recent Brazilian study by (29), they found that the $G$ allele was independently associated with an increased risk of mildly to moderately eGFR (G3a) and kidney failure (G5). 
Results of logistic regression analysis revealed that UACR was much more associated with the presence of GG genotype than eGFR this finding is consistent with a study by Myśliwska et al (30); they revealed that IL-10 was the strongest independent predictor of albuminuria in DKD patients.

In line with this assumption, an increasing number of studies have reported an association between alterations in the interleukin gene and diabetes mellitus. For example, Mandke and Singh (31) reported that elevated expression of IL-10 played a protective role in autoimmune diabetes in mice. On the contrary, Habash et al,(32) suggested that this proinflammatory cytokine promoted mitochondrial function and neurite outgrowth in cultured adult sensory neurons derived from normal and diabetic rats, while $\boldsymbol{X} \boldsymbol{u}$ et $\boldsymbol{a l}$, (24) reported that IL-10 gene transfer downregulated the expression of inflammatory cytokines, attenuated pancreatic insulitis, and inhibited $\beta$ cell apoptosis, thereby reducing the incidence of diabetes in female nonobese diabetic mice.

Also, serum levels of IL-10 were lower in Chinese patients with ESRD as compared with healthy individuals. In addition, the AA genotype was associated with the increased risk of ESRD, and among patients, the serum levels of IL-10 in homozygotes for the A allele of the $1082 \mathrm{~A}>\mathrm{G}$ polymorphism were lower than in the $\mathrm{G}$ allele carriers. However, the up-regulation of IL-10 has been associated with various kidney diseases and high circulating IL-10 levels were found in diabetic patients and in those with macroalbuminuria or chronic kidney disease in type 2 diabetes (33).

This study had some limitation. First, the studied subjects were recruited from one area, which may not accurately represents those from other regions. Second, the sample size included in this study was relatively small, that may affect the detection of a statistically significant difference between groups. Further large longitudinal cohort studies are still required to validate our findings.

\section{Conclusion}

The IL-10 (1082) G/A gene polymorphism was found to be associated with the risk of developing of diabetic kidney disease in Egyptian type 2 diabetic patients. Moreover, the risk of developing DKD, due to IL-10 (1082) G/A gene polymorphism, is the same in both albuminuric and non albuminuric Egyptian type 2 diabetic kidney patients.

\section{Recommendations}

1- To perform a multicentric study that will help in increasing the statistical power, alleviate possible differences of studied subjects, as the ethnicity, gene-environment interaction including economic and nutritional status, as well as differences in the duration of diabetes.

2- Future studying of IL-10 (1082) G/A gene polymorphism with IL-10 gene $819 \mathrm{C} / \mathrm{T}$ and $592 \mathrm{C} / \mathrm{A}$ polymorphisms, which might have synergistic effects on increasing the risk of developing DKD, as well as the progression of the disease in type 2 diabetic patients.

3- Using DNA sequencing technique for detection of different IL-10 gene polymorphisms will increase accuracy of the results.

4- Early diagnosis of DKD patients during non albuminuric stage, may keep kidney disease from getting worse.

5- Controlling blood pressure, glycemic level and albuminuria will contribute in slowing disease progression. 


\section{References}

1. Afkarian, M. et al. (2013): Kidney disease and increased mortality risk in type 2 diabetes. J. Am. Soc. Nephrol. 24, 302-308.

2. Dwyer J. P. et al. (2012): Renal dysfunction in the presence of normoalbuminuria in type 2 diabetes: results from the DEMAND study. Cardiorenal Med. 2, 1-10.

3. Mogensen, C. E., Christensen, C. K. \& Vittinghus, E. (1983): The stages in diabetic renal disease. With emphasis on the stage of incipient diabetic nephropathy. Diabetes 32 (Suppl. 2), 64-78.

4. Thomas, M. C., Weekes, A. J., Broadley, O. J., Cooper, M. E. \& Mathew, T. H. (2006): The burden of chronic kidney disease in Australian patients with type 2 diabetes (the NEFRON study). Med. J. Australia 185, 140-144.

5. Retnakaran, R. et al. (2006): Risk factors for renal dysfunction in type 2 diabetes: U. K. Prospective Diabetes Study 74. Diabetes 55, 1832-1839.

6. Molitch, M. E. et al. (2010): Development and progression of renal insufficiency with and without albuminuria in adults with type 1 diabetes in the diabetes control and complications trial and the epidemiology of diabetes interventions and complications study. Diabetes Care 33, 1536-1543.

7. Tuttle KR (2005): Linking metabolism and immunology: Diabetic nephropathy is an inflammatory disease. J Am Soc Nephrol 16: 1537-1538.

8. Mosser DM \& Zhang X (2008): Interleukin-10: new perspectives on an old cytokine. Immunol Rev. Dec;226:205-18.

9. Yin Q, Zhai Q, Wang D, Hai J, Cao M, Wang J, Wang T (2015): Investigation on the association between inerleukin-10 -592C/A, 819C/T and 1082A/G gene polymorphisms and development of diabetic nephrophathy. Int J Clin Exp Pathol; 8:15216-15221.

10. Levey AS, Coresh J, Greene T., et al. (2006): Using standardized serum creatinine values in the Modification of Diet in Renal Disease study equation for estimating glomerular filtration rate. Ann Intern Med 145: 247-254.

11. National Kidney Foundation (2012): KDOQI clinical practice guideline for diabetes and CKD: update. Am J Kidney Dis; 60(5):850886.

12. Sinuani I, Beberashvili I, Averbukh Z, Sandbank J (2013): Role of IL-10 in the progression of kidney disease. World $\mathbf{J}$ Transplant; 3: 91-98.

13. Saxena A, Khosraviani $S$, Noel $S$, Mohan D, Donner T, Hamad AR (2015): Interleukin-10 paradox: a potent immunoregulatory cytokine that has been difficult to harness for immunotherapy. Cytokine 2015;74:27-34.

14. Erdogan, cetinkalp et al., (2011): interlukin-10 $(-1082 \mathrm{G} / \mathrm{A})$ gene polymorphism in patients with type 2 diabetes with and without nephropathy. GTMB; 16:91-94.

15. Bohlender JM, Franke S, Stein G, Wolf G (2005): Advanced glycation end products and the kidney. Am J Physiol Renal Physiol. 289:F645-F659.

16. Penno G, Solini A., et al. (2011): Clinical significance of nonalbuminuric renal impairment in type 2 diabetes. Journal of Hypertension; 29(9):1802- 1809.

17. Mottl AK, Kwon KS, Mauer M, Mayer-Davis EJ, Hogan SL, Kshirsagar AV (2013): Normoalbuminuric diabetic kidney disease in the U.S. population. J Diabetes Complications; 27(2): $123 \pm 7$

18. Roberto Trevisan, Alessandro R. Dodesini and Giuseppe Lepore (2006): Lipids and Renal Disease. JASN; 17 (4 suppl 2) S145-S147.

19. Bakris GL, Weir MR, Shanifar S, Zhang Z, Douglas J, van Dijk DJ, et al. (2003): Effects of blood pressure level on progression of diabetic nephropathy: Results from the RENAAL study. Archives of Internal Medicine. 163(13):15551565

20. Padmaja K Rani, Rajiv Raman (2011): Albuminuria and Diabetic Retinopathy in Type 2 Diabetes Mellitus. Sankara Nethralaya Diabetic Retinopathy Epidemiology And Molecular Genetic Study Diabetology \& Metabolic Syndrome 3:9.

21. Adler AI, Stevens RJ, Manley SE, Bilous RW, Cull CA (2003): UKPDS GROUP: Development and progression of nephropathy in type 2 diabetes: The United Kingdom Prospective Diabetes Study (UKPDS 64). Kidney Int 63: 225-232.

22. Brenner BM, Lawler EV, Mackenzie HS (1996): The hyperfiltration theory: a paradigm shift in nephrology. Kidney Int. 1996; 49: 1774-1777.

23. MacIsaac., et al. (2014): Progressive diabetic nephropathy. How useful is microalbuminuria?: contra Kidney International Volume 86, Issue 1, Pages 50-57.

24. Xu A, Zhu W, Li T, Li X., et al. (2015): Interleukin-10 gene transfer into insulinproducing $\beta$ cells protects against diabetes in non-obese diabetic mice. Mol. Med. Rep. 12: 3881-3889.

25. Babel $\mathrm{N}$, Gabdrakhmanova L, Hammer $\mathrm{MH}$, Schoenemann C, Skrypnikov V., et al. (2006): Predictive value of cytokine gene polymorphisms for the development of endstage renal disease. J Nephrol; 19:802-807.

26. Ma DH, Xu QY, Liu Y, Zhai QQ, Guo MH (2015): Association between interlukin 10 gene polymorphisms and susceptibility to diabetic nephropathy in a Chinese population. Genet. Mol. Res. 15 (2): gmr.15027570.

27. Dace D.S., Khan A.A., Kelly J., Apte R.S (2009): Interleukin-10 Promotes Pathological Angiogenesis by Regulating Macrophage Response to Hypoxia during Development, PLoS One; 4, e7121.

28. Timasheva Y. R., Nasibullin T. R., Zakirova A. N., Mustafina O. E. (2008): Association of Interleukin-6, Interleukin-12, and Interleukin-10 
Gene Polymorphisms with Essential Hypertension in Tatars from Russia.

29. Polina ER, Pereira BL, Crispim D, Sbruzzi RC, Canani LH, Santos KG (2017): Association Between $-1082 \mathrm{~A}>\mathrm{G}$ Polymorphism and Egfr in type 2 diabetes. Kidney Blood Press Res. 42:1164-1174.

30. Myśliwska J, Zorena $\mathrm{K}$, SemetkowskaJurkiewicz E., et al. (2005): High levels of circulating interleukin-10 in diabetic nephropathy patients. Eur Cytokine Netw. 16(2):117-22.

31. Mandke R and Singh J (2012): Cationic nanomicelles for delivery of plasmids encoding interleukin-4 and interleukin-10 for prevention of autoimmune diabetes in mice. Pharm. Res. 29: 883-897.

32. Habash T, Saleh A, Roy Chowdhury SK, Smith DR., et al. (2015): The proinflammatory cytokine, interleukin-17A, augments mitochondrial function and neurite outgrowth of cultured adult sensory neurons derived from normal and diabetic rats. Exp. Neurol. 273: 177189.

33. Kung WJ, Lin CC, Liu SH, Chaung HC (2010): Association of interleukin-10 polymorphisms with cytokines in type 2 diabetic nephropathy. Diabetes Technol Ther. 12: 809-81

To cite this article: Amany S Elshamy ${ }^{\mathrm{a}}$, Mohamed M. Elshafae ${ }^{\mathrm{b}}$, Hesham A. Eissa ${ }^{\mathrm{b}}$, Asmaa A. Elfallah $^{\text {b }}$, Saddam H. Abdelazizc (2019); Association Between Interlukin 10 Gene Polymorphism And Susceptibility To Diabetic Kidney Disease BMFJ 2019:36(2) DOI: 10.21608/bmfj.2019.16833.1054 